\title{
NOTA PRÉVIA
}

\section{TRYPANOSOMA CRUZI NO COLOSTRO HUMANO}

\section{Maria das Dores Medina-Lopes e Vanize Macêdo}

Estamos relatando à comunidade científica a comprovação pela primeira vez da presença de T. cruzi no colostro humano.

Uma paciente de 22 anos apresentou a forma aguda da doença de Chagas em março de 1983. Em 18/04/83, quinta semana da doença, o exame direto do colostro não demonstrou parasitas, sendo feito então a inoculação de $0,2 \mathrm{ml}$ deste colostro em cada um de dois camundongos fêmeas de 30 dias através da via intraperitoneal. Quinze dias após os camundongos foram submetidos a xenodiagnósticos utilizando-se cinco espécimes de Dipetalogaster maximus, em cada um. A leitura foi realizada 42 dias após o repasto. As fezes de cada triatomíneo foram examinadas isoladamente e todas foram positivas para $T$. cruzi.

A paciente teve parto normal em 22/04/83 sendo o recém-nascido normal, do sexo feminino, - com características de pretermo (Capurro: 36 semanas e 5 dias). Não se demonstrou a transmissão ao recém-nascido, sendo os exames persistentemente negativos em quatro diferentes métodos diagnósticos.

A amamentação com leite materno foi proscrita no momento do parto.

O leite desta paciente, obtido em 25 e 29 /
04/83, foi inoculado em camundongos, por via intraperitoneal, e 10 dias após os xenodiagnósticos foram positivos.

A presença de $T$. cruzi no leite humano foi relatada pela primeira vez por Míazza em 1936! Este autor diagnosticou a fase aguda da doença de Chagas em uma gestante e pesquisou o parasita no recém-nascido através do método direto, dez dias após o parto com resultados negativos. Aos três meses de idade a criança apresentou manifestações da fase aguda da doença de Chagas, com abundantes flagelados em sangue periférico. Nesta mesma época o $T$. cruzi foi encontrado no sedimento do leite materno.

Na paciente por nós estudada o $T$. cruzi foi encontrado no colostro e no leite materno.

Devido à possibilidade de transmissão da doença de Chagas através do leite recomendamos que mães na fase aguda desta doença não amamentem os seus filhos.

\section{REFERẼNCIA BIBLIOGRĀFICA}

1. Mazza S, Montana A, Benitez C, Janzi EZ. Transmision del Schizotrypanum cruzi, al niño por leche de la madre con enfermedad de Chagas. MEPRA 28:41 . $-46,1936$. 